\title{
A REVISED SECOND-ORDER DISCRETIZATION OF THE 2-D ELASTIC BEAM ELEMENT*
}

\author{
Masahiro AI ${ }^{1}$, Kentaro TAMURA ${ }^{2}$ and Fumio NISHINO ${ }^{3}$ \\ ${ }^{1}$ Mem. of JSCE, Dr.Eng., Professor, Dept. of Civil Engng., Hosei Univ. \\ (Koganei Tokyo 184, Japan) \\ 2 Mem. of JSCE, Grad. Student, Dept. of Civil Engng., Hosei Univ. \\ (Koganei Tokyo 184, Japan) \\ ${ }^{3}$ Mem. of JSCE, Ph.D., Professor, Grad. School of Policy Science, Saitama Univ.
}

(Urawa Saitama 338, Japan)

\begin{abstract}
In the FEM formulation of a plane beam element, the interpolation is improved toward consistency with the beam-column theory. The geometrical effects of the flexural and axial displacements upon the longitudinal strain are explicitly analyzed in up to their second-order terms. The flexural displacement is framed, as usual, in the cubic-polynomoal distributions, the magnitudes of which are linear with the nodal parameters. But, in the interpolation of the axial displacement, the secondary effects of the flexural displacement are taken into account, which are expressed in a quadratic form of the deflection parameters.
\end{abstract}

Key Words : second-order discretization, beam-column theory, interpolation

\section{INTRODUCTION}

In the recent structural analyses, it seems essential for the elements to be developed into more or less nonlinear stiffness relations. Since an exact solution is difficult in general to be obtained, there have been presented the secondorder formulations for various types of elements. Their applications are not restricted only to those problems lying in a range of relatively small displacements. But, truly large displacements can also be deal with, by their incorporation with the up-dated Lagrangian description or with the method of separation-into-rigiddisplacement-and-deformation.

So far as the plane beam element is concerned, since before the age of computational methods, there has been the beam-column theory. In the evolution of matrix methods, the flexural effect

* A main part of this paper has been presented at the JSCE Annual Conference, ${ }^{9}$ ) held in Nagoya, 1996-9. of axial force was first estimated by Hartz ${ }^{3)}$ into the geometrical stiffness matrix. But, as known today, the resulting is a set of linearlized relations upon an initial state of axial compression or tension. Nowadays, the second order terms are derived in the following two methods, in principle: One method is to rewrite the slope-deflection equations known in the beam-column theory into a matrix form e.g. $1,2,4,7,8$ ). In this treatment, the flexural effect by an axial force is contained exactly upon the initial state, but the stiffness equation to determine the axial force becomes implicit in terms of the nodal displacements. The other ones are based on the finite element procedure. In the existing formulations for that second-order problem, to be noted, the displacements within an element are still interpolated in a linear form of the nodal parameters e.g. 5,6 ).

In this study, a revision is presented in the second-order FEM formulation of a plane beam element. The second effect of the beam deflection 
onto the axial elongation is exactly taken into account: in the interpolation of the axial displacement, the quadratic terms of the deflection parameters are added to the linear ones. With the use of the same potential energy function, the resulting stiffness relations are consistent with the differential equations in the beam-column theory.

\section{KINEMATIC FIELD}

Under the Bernoulli-Euler hypothesis, we consider a straight beam deformed in a range of small elastic strains. In the initial state, the spatial $x$-axis is taken onto the centroidal line of crosssection (G-line), with $y$-axis taken parallel to the cross section. The displacement components of that axial line into $\{x, y\}$ are here denoted by $\left\{u_{G}(x), v_{G}(x)\right\}$. In terms of those components, the axial elongation (a normal component of the Green's strain) is, to be exact, written as

$$
e_{G x x}=\frac{d u_{G}}{d x}+\frac{1}{2}\left\{\left(\frac{d u_{G}}{d x}\right)^{2}+\left(\frac{d v_{G}}{d x}\right)^{2}\right\}
$$

From this expression, where $u_{G}(x)$ and $v_{G}(x)$ are independent to each other, the flexural $v_{G}(x)$ can be larger than $u_{G}(x)$. The normal strains by the bending (at edges of cross-section) are assumed of the same order :

$$
h \frac{d^{2} v_{G}}{d x^{2}} \simeq \frac{h v_{G}}{l^{2}} \simeq \epsilon
$$

where $h$ and $l$ are height of cross-section and beam length; and $\epsilon$ is an allowable magnitude of small strains. Eventually, the axial and flexural displacements are related as follows :

$$
\frac{u_{G}}{l} \simeq\left(\frac{v_{G}}{l}\right)^{2} \simeq\left[\frac{h}{l}\right]^{2} \simeq \epsilon
$$

Neglecting higher terms than $\epsilon$ with respect to unity, we have the results well known in the beamcolumn theory: The displacement components on cross-section are written as

$$
\begin{aligned}
& u(x, y)=u_{G}(x)-y \frac{d v_{G}}{d x} \\
& v(x, y)=v_{G}(x)
\end{aligned}
$$

This expression is the same to the smalldisplacement theory. But, the normal strains on cross-section are given by

$$
e_{x x}(x, y)=\frac{d u_{G}}{d x}+\frac{1}{2}\left(\frac{d v_{G}}{d x}\right)^{2}-y \frac{d^{2} v_{G}}{d x^{2}}
$$

We next consider an associated discretization of the beam element, say $(e)$. In terms of its nodal displacements

$$
\{\boldsymbol{u}\}_{(e)}=\left\{(u, v, \theta)_{i},(u, v, \theta)_{j}\right\}
$$

the flexural displacement is interpolated in the same way to the small displacement theory :

$$
\begin{gathered}
v_{G}(\xi)=\left\langle\Phi_{v}\right\rangle\left\{(v, \theta)_{i},(v, \theta)_{j}\right\} \\
\left\langle\Phi_{v}\right\rangle=\left\langle 1-3 \xi^{2}+2 \xi^{3}, l\left(\xi-2 \xi^{2}+\xi^{3}\right)\right. \\
\left.3 \xi^{2}-2 \xi^{3}, l\left(-\xi^{2}+\xi^{3}\right)\right\rangle
\end{gathered}
$$

where $\xi=x / l$.

In the present kinematic field, however, the flexural $v_{G}(\xi)$ is relatively large, as given by (3). If this $v_{G}(\xi)$ takes place with no elongation of the axial line, namely $e_{x x}(x, 0)=0$ in (5), there must be the axial displacement given by

$$
\begin{aligned}
u_{G}^{*}(\xi)= & -\frac{1}{2 l} \int_{0}^{\xi}\left(\frac{d v_{G}}{d \xi}\right)^{2} d \xi \\
= & -\left\langle(v, \theta)_{i},(v, \theta)_{j}\right\rangle \\
& {\left.\left[\frac{1}{2 l} \int_{0}^{\xi}\left\{\frac{d \Phi_{v}}{d \xi}\right\}\left\langle\frac{d \Phi_{v}}{d \xi}\right\rangle d \xi\right]\left\{\begin{array}{c}
v \\
\theta \\
v \\
\theta
\end{array}\right)_{j}\right\} }
\end{aligned}
$$

By the actual integration, the shortening in the entire span is obtained as

$$
\begin{aligned}
\Delta= & \frac{1}{2}\left\langle(v, \theta)_{i},(v, \theta)_{j}\right\rangle \\
\text { or } & {\left[\begin{array}{cccc}
\frac{6}{5 l} & \frac{1}{10} & \frac{-6}{5 l} & \frac{1}{10} \\
& \frac{2 l}{15} & \frac{-1}{10} & \frac{-l}{30} \\
& \frac{6}{5 l} & \frac{-1}{10} \\
\text { Sym. } & \frac{2 l}{15}
\end{array}\right]\left\{\left(\begin{array}{c}
v \\
\theta \\
v \\
\theta
\end{array}\right)_{j}\right\} } \\
& =\frac{1}{30 l}\left\{\begin{array}{c}
18\left(v_{i}-v_{j}\right)^{2}+3 l\left(\theta_{i}+\theta_{j}\right)\left(v_{i}-v_{j}\right) \\
\left.+l^{2}\left(2 \theta_{i}^{2}+2 \theta_{j}^{2}-\theta_{i} \theta_{j}\right)\right\}
\end{array}\right.
\end{aligned}
$$

On the other hand, in case the axial displacements are fixed at the both ends, for the lateral $v_{G}(\xi)$, there simultaneously takes place a uniform elongation $\xi \Delta$ to hold the compatibility. As 
shown in Fig.1, by the sum of those second effects onto the linear terms for $\left\{u_{i}, u_{j}\right\}$, we have the axial displacement interpolated in the following form :

$$
u_{G}(\xi)=\langle 1-\xi, \xi\rangle\left\{\begin{array}{c}
u_{i} \\
u_{j}
\end{array}\right\}+u_{G}^{*}(\xi)+\xi \Delta
$$

As the result, in expression (5) for $e_{x x}$, the $u_{G}^{*}(\xi)$ contained in $u_{G}(\xi)$ is canceled by the square term of $d v_{G} / d x$. The normal strain on the axial line is given by

$$
e_{G x x}=\frac{1}{l}\left\{u_{j}-u_{i}+\Delta\right\}: \text { const. }
$$
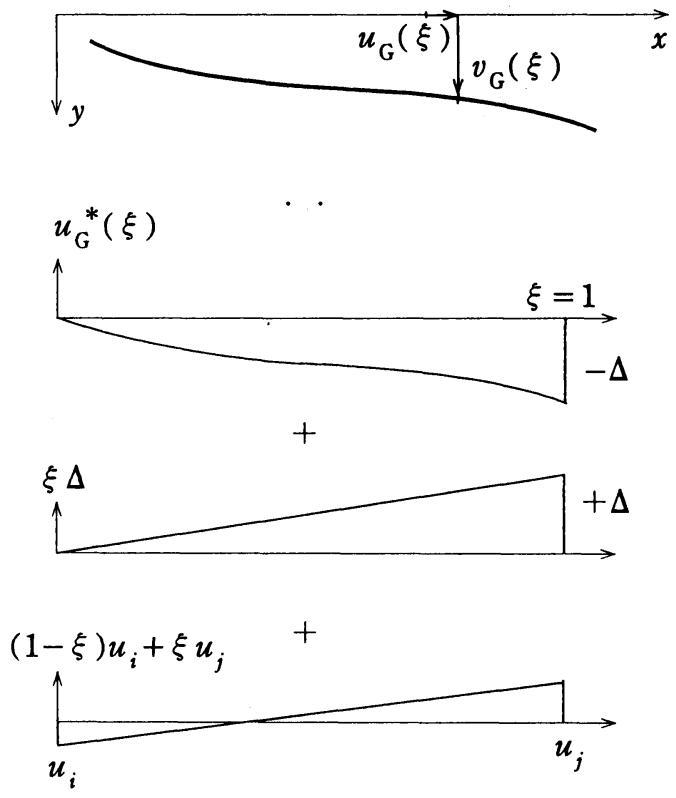

Fig. 1 Decomposition of axial displacement

\section{STIFFNESS RELATIONS}

The axial force and the bending moment in cross-section are related to the displacements of the axial line, as follows :

$$
\begin{aligned}
& N\left(=E \int e_{x x} d A\right)=E A\left\{\frac{d u_{G}}{d x}+\frac{1}{2}\left(\frac{d v_{G}}{d x}\right)^{2}\right\} \\
& M\left(=E \int y e_{x x} d A\right)=-E I \frac{d^{2} v_{G}}{d x^{2}}
\end{aligned}
$$

The total potential energy of the beam element sujected to external forces $\left\{F_{x}, F_{y}\right\}$ and moments
$M$ at the both ends is written as

$$
\begin{aligned}
W= & \int_{0}^{l}\left[\frac{M^{2}}{2 E I}+\frac{N^{2}}{2 E A}\right] d x \\
& -\left.\left\{F_{x} u_{G}+F_{y} v_{G}+M \theta\right\}\right|_{x=0} \\
& -\left.\left\{F_{x} u_{G}+F_{y} v_{G}+M \theta\right\}\right|_{x=l}
\end{aligned}
$$

After interpolation (7) and (10) introduced into (13), the stationary condition for variation $\delta\{\boldsymbol{u}\}_{(e)}$ is written as

$$
\begin{gathered}
\delta W=\int_{0}^{1}\left[\left\langle(v, \theta)_{i},(v, \theta)_{j}\right\rangle \frac{E I}{l^{3}}\left\{\frac{d^{2} \Phi_{v}}{d \xi^{2}}\right\} .\right. \\
\left\langle\frac{d^{2} \Phi_{v}}{d \xi^{2}}\right\rangle\left\{\begin{array}{l}
\left(\begin{array}{c}
\delta v \\
\delta \theta
\end{array}\right)_{i} \\
\left(\begin{array}{c}
\delta v \\
\delta \theta
\end{array}\right)_{j}
\end{array}\right\} \\
\left.+\frac{E A}{l}\left\{u_{j}-u_{i}+\Delta\right\}\left\{\delta u_{j}-\delta u_{i}+\delta \Delta\right\}\right] d \xi \\
-\{\boldsymbol{F}\}_{(e)}^{T} \delta\{\boldsymbol{u}\}_{(e)}=0
\end{gathered}
$$

Substituting the variation of the shortening $\Delta$ given by (9), by the arbitrariness of $\delta\{\boldsymbol{u}\}_{(e)}$, we have the following nodal force-nodal displacement relations :

$$
\begin{aligned}
& -F_{x i}=F_{x j}=N \\
& \left\{\begin{array}{l}
\left(\begin{array}{c}
F_{y} \\
M
\end{array}\right)_{i} \\
\left(\begin{array}{c}
F_{y} \\
M
\end{array}\right)_{j}
\end{array}\right\}=\left(\left[k_{0}\right]\right. \\
& \left.+N\left[\bar{k}_{G}\right]\right)\left\{\begin{array}{l}
\left(\begin{array}{l}
v \\
\theta
\end{array}\right)_{i} \\
\left(\begin{array}{c}
v \\
\theta
\end{array}\right)_{j}
\end{array}\right\}
\end{aligned}
$$

where

$$
\begin{aligned}
N & =\frac{E A}{l}\left\{u_{j}-u_{i}+\Delta\right\} \\
{\left[k_{0}\right] } & =\frac{E I}{l^{3}}\left[\begin{array}{cccc}
12 & 6 l & -12 & 6 l \\
& 4 l^{2} & -6 l & 2 l^{2} \\
& & 12 & -6 l \\
\text { Sym. } & & & 4 l^{2}
\end{array}\right]
\end{aligned}
$$




$$
\left[\bar{k}_{G}\right]=\left[\begin{array}{cccc}
\frac{6}{5 l} & \frac{1}{10} & \frac{-6}{5 l} & \frac{1}{10} \\
& \frac{2 l}{15} & \frac{-1}{10} & \frac{-l}{30} \\
& & \frac{6}{5 l} & \frac{-1}{10} \\
\text { Sym. } & & & \frac{2 l}{15}
\end{array}\right]
$$

Those $N,\left[k_{0}\right]$ and $\left[\bar{k}_{G}\right]$ indicate the uniform axial force, the initial stiffness in bending and the geometrical stiffness per unit axial force, respectively.

By differentiating the above (15) and (16) with respect to the nodal displacements, we have the tangent stiffness relations :

$$
\begin{aligned}
& -\delta F_{x i}=\delta F_{x j}=\frac{E A}{l}\left(\delta u_{j}-\delta u_{i}\right) \\
& +\frac{E A}{l}\left\langle\psi^{*}(v, \theta)\right\rangle\left\{\begin{array}{l}
\left(\begin{array}{c}
\delta v \\
\delta \theta
\end{array}\right)_{i} \\
\left(\begin{array}{c}
\delta v \\
\delta \theta
\end{array}\right)_{j}
\end{array}\right\} \\
& \left\{\begin{array}{l}
\left(\begin{array}{l}
\delta F_{y} \\
\delta M
\end{array}\right)_{i} \\
\left(\begin{array}{c}
\delta F_{y} \\
\delta M
\end{array}\right)_{j}
\end{array}\right\}=\left(\left[k_{0}\right]+N\left[\bar{k}_{G}\right]\right. \\
& \left.+\frac{E A}{l}\left[\left\{\psi^{*}(v, \theta)\right\}\left\langle\psi^{*}(v, \theta)\right\rangle\right]\right)\left\{\begin{array}{l}
\left(\begin{array}{l}
\delta v \\
\delta \theta
\end{array}\right)_{i} \\
\left(\begin{array}{l}
\delta v \\
\delta \theta
\end{array}\right)_{j}
\end{array}\right\} \\
& +\frac{E A}{l}\left\{\psi^{*}(v, \theta)\right\}\left(\delta u_{j}-\delta u_{i}\right)
\end{aligned}
$$

where

$$
\begin{aligned}
& \left.\left\{\psi^{*}(v, \theta)\right\}=\left[\bar{k}_{G}\right]\left\{\begin{array}{l}
\left(\begin{array}{l}
v \\
\theta
\end{array}\right)_{i} \\
\left(\begin{array}{c}
v \\
\theta
\end{array}\right)_{j}
\end{array}\right\}\right) \\
& =\left\{\begin{array}{c}
\frac{6}{5 l}\left(v_{i}-v_{j}\right)+\frac{1}{10}\left(\theta_{i}+\theta_{j}\right) \\
\frac{1}{10}\left(v_{i}-v_{j}\right)+\frac{l}{30}\left(4 \theta_{i}-\theta_{j}\right) \\
\frac{6}{5 l}\left(v_{j}-v_{i}\right)-\frac{1}{10}\left(\theta_{i}+\theta_{j}\right) \\
\frac{1}{10}\left(v_{i}-v_{j}\right)+\frac{l}{30}\left(4 \theta_{j}-\theta_{i}\right)
\end{array}\right\}
\end{aligned}
$$

By the integration of $\delta U_{(e)}=\left(F_{x} \delta u+F_{y} \delta v+\right.$ $M \delta \theta)_{i}+(\cdots)_{j}$, we have the strain energy function of element $(e)$ :

$$
\begin{aligned}
& U_{(e)}=\frac{E A}{2 l}\left(u_{j}-u_{i}+\Delta\right)^{2} \\
& +\frac{1}{2}\left\langle(v, \theta)_{i},(v, \theta)_{j}\right\rangle\left[k_{0}\right]\left\{\begin{array}{l}
\left(\begin{array}{c}
v \\
\theta
\end{array}\right)_{i} \\
\left(\begin{array}{l}
v \\
\theta
\end{array}\right)_{j}
\end{array}\right\}
\end{aligned}
$$

\section{NUMERICAL EXAMPLE}

A slender beam element is considered: $l=500$. $\mathrm{cm}, E=2,100$. tonf $/ \mathrm{cm}^{2}, A=26.84 \mathrm{~cm}^{2}$, and $I=151 . \mathrm{cm}^{4}$. First, with node i being fixed in a cantilever support, a vertical $F_{y j}$ is applied up to 1 . tonf at the other node (see Fig.2). The resulting displacements $(u, v, \theta)_{j}$ are shown in Fig.3: the lines with symbol $\square, \bigcirc$ and $\triangle$ indicate the present second-order relations; and the plain lines are a result regarded as numerically exact, obtained by the separation method ${ }^{10)}$ with a segmentation into ten elements.

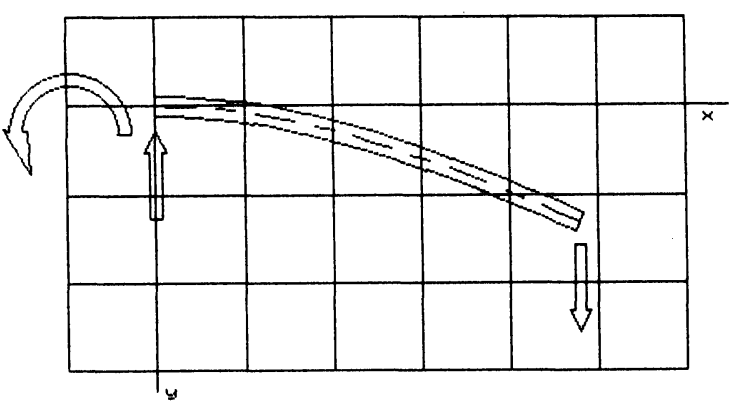

Fig. 2 Deformed configuration at $F_{y j}=1$. tonf

Next, after subjected to a preceding axial force $F_{x j}\left(=-1 / 3 \cdot \pi^{2} E I / l^{2}\right)=-4.17$ tonf, in a simple support, an additional $M_{i}$ is applied up to 1,000. tonf.cm at node i (see Fig.4). The displacements $\left(u_{j}, \theta_{i}, \theta_{j}\right)$ are shown in Fig.5. Those lines of displacements seem lying in a good approximation. But, for example, if $\left(u_{j}, \theta_{i}, \theta_{j}\right)=(-1.23 \mathrm{~cm}, 0.139,-0.083)$ obtained at $\left(F_{x j}, M_{i}, M_{j}\right)=(-4.17$ tonf, 200 ., 0. tonf $\cdot \mathrm{cm})$ in the numerically exact analysis are estimated by the second-order relations, the nodal forces are $\left(F_{x j}, M_{i}, M_{j}\right)=(-18.6$ tonf, $48.6,111.7$ tonf $\cdot \mathrm{cm})$. If subjected to no axial force, in the same comparison, the nodal forces for $\left(u_{j}, \theta_{i}, \theta_{j}\right)=$ $(-0.55 \mathrm{~cm}, 0.105,-0.053)$ at $\left(F_{x j}, M_{i}, M_{j}\right)=$ 


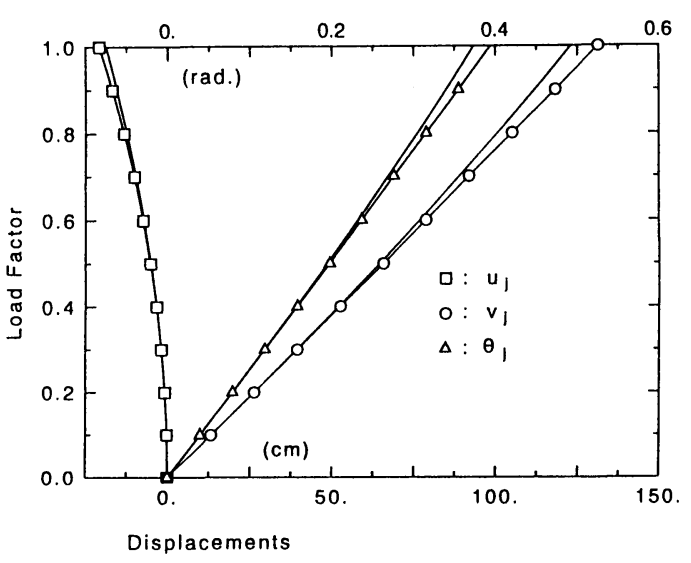

Fig. 3 Displacements at the free end

(0.tonf, 200., 0.tonf $\cdot \mathrm{cm}$ ) are approximated by $\left(F_{x j}, M_{i}, M_{j}\right)=(0.02$ tonf, $200.2,-0.07$ tonf $\cdot \mathrm{cm})$. In the present stiffness relations, the flexural relations between $\left\{\left(F_{y}, M\right)_{i},\left(F_{y}, M\right)_{j}\right\}$ and $\left\{(v, \theta)_{i},(v, \theta)_{j}\right\}$ are linear for a given axial force. Together with the three straight lines for $F_{x j}=-4.17,0$. and 4.17 tonf, Figure 6 shows a curved response of angular displacement $\theta_{i}$ in a loading $\left(F_{x j}, M_{i}\right)=(-4.17,0)+.\rho(8.34,1000$.$) ,$ $0 . \leq \rho \leq 1$.

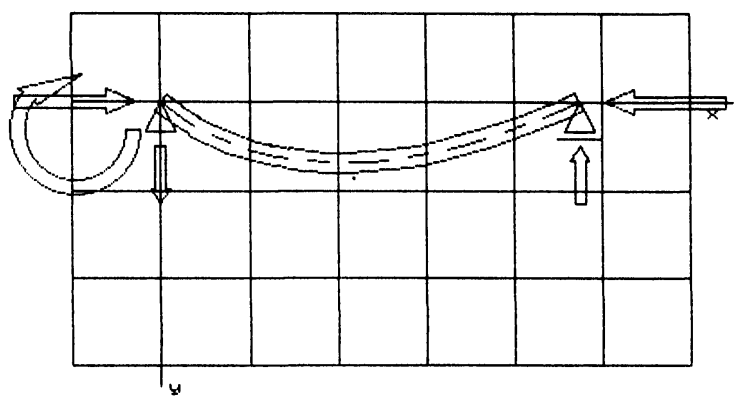

Fig. 4 Deformed configuration at $\left(F_{x j}, M_{i}\right)=$ $(-4.17$ tonf, 1000 . tonf $\cdot \mathrm{cm})$

\section{CONCLUDING REMARKS}

As for a plane beam element, the third-order terms were already presented in Ref.[10], which are derived by the perturbation technique applied to the governing differential equations for truly large displacements. Within the second-order terms, the present stiffness relations through (15) to (19) coincide with the perturbation result. The second-order relations are usually said valid for

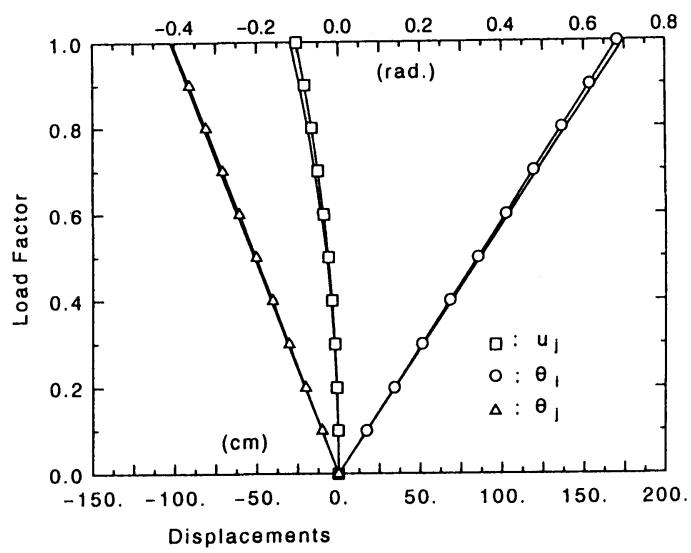

Fig. 5 Displacements in the simple support

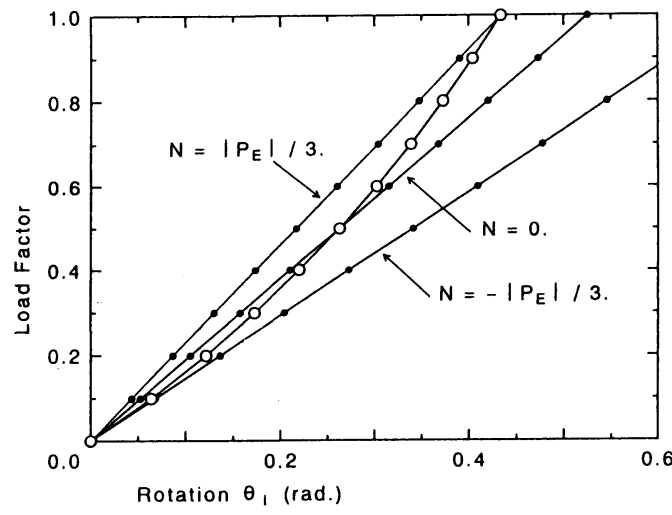

Fig. 6 A curved $\theta_{i}$ in change of axial force

deflection angles less than $10^{\circ}$ e.g. 9). But, as shown in the former example, if subjected to a certain axial force such as a fraction of the Euler buckling load, the accuracy is not sufficient. This defect is, of course, improved by a subdivision into smaller segments. To derive nonlinear stiffness relations, there might be other preferable methods for some particular elements, but the second-order formulation through the FEM procedure seems a consistent method applicable to a wide variety of structural elements.

\section{REFERENCES}

1) Saafan, S.A.: Nonlinear behavior of structural plane frames, J. Struct. Div., ASCE, Vol.89, No.ST4, pp.557-579, Aug., 1963.

2) Saafan, S.A.: closure to "Nonlinear behavior of structural plane frames," J. Struct. Div., ASCE, Vol.91, No.ST1, pp.279-281, Feb., 1965. 
3) Hartz, B.J.: Matrix formulation of structural stability problems, J. Struct. Div., ASCE, Vol.91, No.ST6, pp.141-157, Dec., 1965.

4) Connor, J.J., Logcher, R.D. and Chan, S.C.: Nonlinear analysis of elastic framed structures, $J$. Struct. Div., ASCE, Vol.94, No.ST6, pp.1525-1547, Jun., 1968.

5) Mallet, R.H. and Marcal, P.V.: Finite element analysis of nonlinear structures, J. Struct. Div., ASCE, Vol.94, No.ST9, pp.2081-2105, Sep., 1968.

6) Maeda, Y., Hayashi, M. and Nakamura, M.: An acceleration approach for large deformation structural analysis by incremental method, Proceedings of JSCE, No.223, pp.1-9, 1974-3 (in Japanese). J. Struct. Div., ASCE, Vol.99, No.ST6, pp.973-985,

7) Goto, S., Hane, G. and Tanaka, T.: Tangent stiffness method for large deformation analysis of frame structure, Proceedings of JSCE, No.238, pp.31-42, 1975-6 (in Japanese).
8) Goto, Y. and Chen, W.F.: Second-order elastic analysis for frame design, J. Struct. Eng., ASCE, Vol.113, No.7, pp.1501-1519, Jul., 1987.

9) Galambos, V. (ed.) : Guide to stability design criteria for metal structures, 4-th ed, John Wiley \& Sons, New York, 1988.

10) $\mathrm{Ai}, \mathrm{M}$. and Nishino, F.: Mechanics in geometrically nonlinear problem of discrete system and application to plane frame-works, Proceedings of JSCE, No.304, pp.17-32, 1980-12 (in Japanese).

11) Ai, M., Tamura, K. and Nishino, F.: A 2nd-order elastic discretization of the plane beam element, Proc. of the Annual Conference, JSCE, pp.140-141, 1996-9 (in Japanese).

(Received March 21, 1997)

\section{平面はり要素の弾性 2 次理論としての一離散化展開 \\ 阿井 正博・田村 健太郎・西野 文雄}

平面はりの弾性 2 次離散化関係には, はり一柱理論のたわみ公式をマトリックス構造解析用に書 き直したもの, および 有限要素法の手順によって離散化展開されるものとがある. 前者は, 曲げ変 形におよぼす軸力の効果を初期状態まわりで正確に現すと考えられるが，その軸力を節点変位に関 して陽な剛性式で表すことができない.ここでは, 後者によるこれまでの結果を見直しながら, 定式 化の最初である変位補間式から一貫した 2 次非線形理論としての展開を示しており，はり-柱理論に 整合する 1 つの離散化結果を得ている. 